\title{
Clinical and Radiological Features of Urinary Infection in Childhood
}

\author{
JEAN M. SMELLIE,* M.A., B.M., M.R.C.P., D.C.H. ; C. J. HODSON, $†$ F.R.C.P., F.F.R. ; \\ DAVID EDWARDS, $\dagger$ M.R.C.P., F.F.R. ; I. C. S. NORMAND,* M.A., B.M., M.R.C.P.
}

Brit. med. F., 1964, 2, 1222-1226

Infection of the urinary tract is a common condition in childhood and one which is often overlooked. In a recent large survey significant bacteriuria was found in $1 \%$ of a schoolgirl population, many of these children being symptomless (Kunin et al., 1962). De Luca et al. (1963) found an average delay in diagnosis of 18 months, and only $28 \%$ of Burke's (1961) series were referred with the correct diagnosis.

In recent years we have become aware of typical pyelonephritic scarring in the excretory pyelograms of young children who have been investigated because of a urinary infection. The association with vesico-ureteric reflux in these cases (Hodson and Edwards, 1960) has also been impressive. At the same time the grave consequences of chronic pyelonephritis have attracted increasing attention, and chronic pyelonephritis is recognized as the commonest cause of hypertension and renal failure in young adults (Rosenheim, 1959).

We therefore decided to study the clinical and radiological features of urinary infections in children in the hope that a better understanding of the natural history in this age-group might lead to improved management, the prevention of scarring, and a reduction in chronic pyelonephritis in later life.

\section{Clinical Material and Methods of Diagnosis}

Two hundred children diagnosed as having infections of the urinary tract were seen in the Paediatric Department, University College Hospital, during 1955 to 1963, their ages ranging from 3 days to 12 years. There were 45 newborn infants, in 34 of whom the diagnosis was made in the U.C.H. Obstetric Hospital, about $0.3 \%$ of all births in the hospital during this period. Seven children with abnormalities of the urinary tract were transferred from other hospitals. The cases were otherwise unselected and were seen in the routine practice of the department. In each case the diagnosis was established by the finding of a significant bacterial growth in a fresh clean specimen of urine. On microscopy significant pyuria (more than 10 white cells per high-power field of centrifuged deposit) was always present. The bacteriological method employed was that described by Guttmann and Stokes (1963), which they showed to give results comparable with pour-plate bacterial counting techniques. Catheterization was not performed in the collection of specimens. Five cases are included of sterile pyuria where the history was highly suggestive of urinary infection and the child was already receiving treatment when first seen. Other children not receiving chemotherapy in whom sterile pyuria was found have been excluded.

Both intravenous pyelography and micturating cystourethro- graphy were performed in 153 children, pyelography alone in a further 22, and micturating cystography alone in 12 . Necropsy information is available in one infant dying at 6 weeks. In 12 children, nine of them newborn, investigation was not carried out either because permission was refused or they were lost to follow-up soon after the initial illness.

\footnotetext{
* From the Department of Paediatrics, University College Hospital, London.

†From the Department of Radiology, University College Hospital,

\section{Clinical Findings}

Results of Urine Examination.-The commonest infecting organism on presentation was Escherichia coli (144 cases). Other organisms isolated included Streptococcus faecalis (16), Proteus vulgaris (19), a paracolon organism (12), Streptococcus viridans (2), and Staphylococcus pyogenes (2). Numerous pus cells were demonstrated in all but five cases, and even in these the number exceeded 10 per high-power field of centrifuged deposit. Significant proteinuria was present in 38 children and a trace in 31 . No proteinuria was detected during their presenting infection in 131 cases.

Age and Sex Incidence.-There was an overall sex distribution of 148 females to 52 males $(2.8: 1)$. This female preponderance was more evident over the age of 1 year (Fig. 1), where the ratio was 4.8:1 (101 females to 21 males). Under the age of 1 year, however, there were 47 females to 31 males $(1.5: 1)$.

Fig. 1A shows the age at onset of symptoms, and Fig. 1B the age at presentation. The age of onset was taken as the time when the symptoms which finally brought the child to hospital first started. It appears that urinary infections begin most commonly during the first year of life. Of the 34 newborn infants born in U.C.H. the diagnosis was made in the first week in 13 and between the eighth and the sixteenth day in the

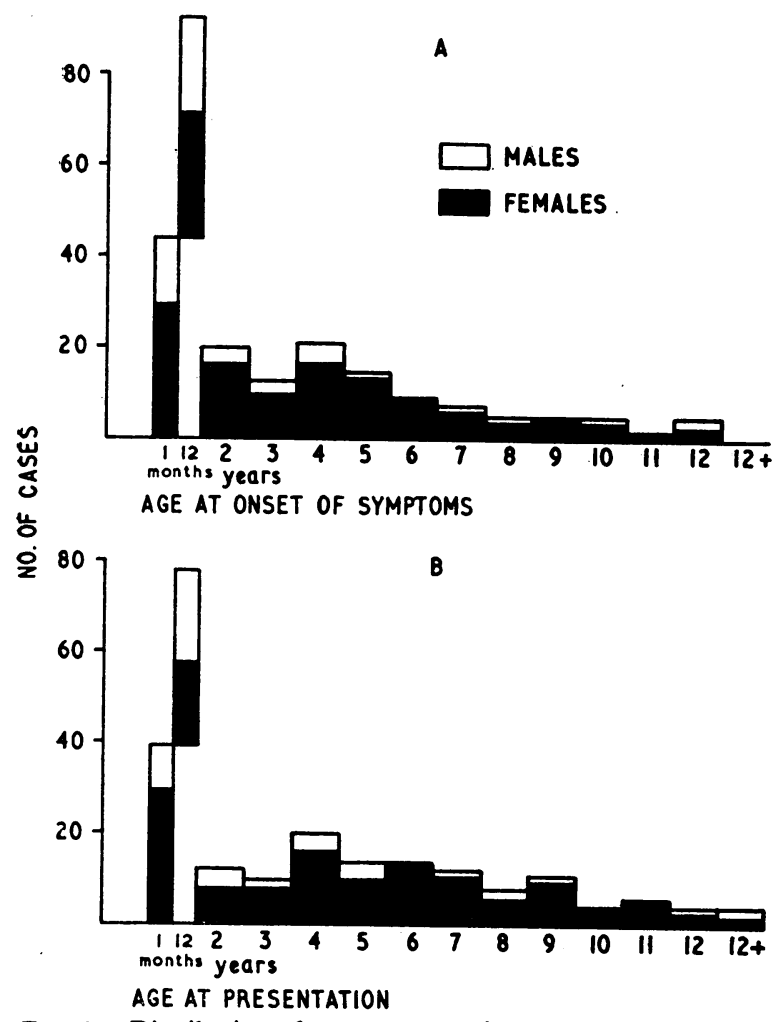

FIG. 1.-Distribution of age at onset of symptoms (A) and age at presentation (B) of 200 children with urinary infection, showing the sex ratio. Chart A shows that in 90 children symptoms began in the first year of life, and in 45 of these they began under the age of 1 month. 
remaining 21. In many cases symptoms were present for some time before the child was first seen in our department, when the diagnosis was established by examination of the urine. In most instances the mother had not sought medical advice, or the diagnosis of urinary infection was unsuspected. On a few occasions treatment had been given without bacteriological control and the child presented with an active urinary infection. This delay and the number of children showing radiological abnormalities are demonstrated in Fig. 2, which also indicates that radiological chronic pyelonephritis was an increasingly common finding with longer delay in presentation.

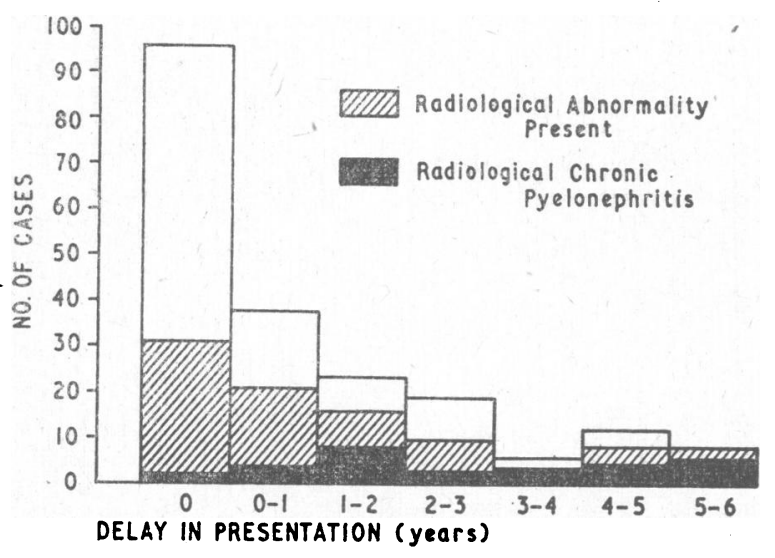

FIG. 2.-Relating the radiological findings to the interval between onset of the child's symptoms and time of presentation Ninety-six children were seen during the first infection and there was no delay in presentation. With longer duration of symptoms there was a higher incidence of radiological chronic pyelonephritis.

Family History.-The series included four pairs of siblings, and two further children had sisters with urinary infection who were not seen by us. The mothers of four children were known to have urinary infections.

Recurrent Infections.-Of the children 104 (70 female, 34 male) presented with apparently their first attack. In the remaining 96, 43 had bacteriological evidence of a previous infection, and in 53 the clinical history was strongly suggestive of previous attacks. The intervals between attacks ranged from a few weeks to four years.

Presenting Diagnosis.-The general lack of recognition of the clinical features of urinary infection in infancy and early childhood is reflected in the presenting diagnoses. Thirty-four infants born and diagnosed in U.C.H. Obstetric Hospital have been excluded from this analysis. Of the remaining 166, only $51(30 \%)$ were referręd to hospital with a suggested diagnosis of urinary infection-in only $9 \%$ of those under 1 year of age, in $42 \%$ between 1 and 2 years, in $32 \%$ between 2 and 5 , and in $42 \%$ between 5 and 12 years.

\section{Symptomatology}

The symptoms of urinary infection vary with age and were therefore analysed in four groups. Group 1, those presenting under the age of 1 month; group 2, those from 1 month to 2 years of age ; group 3, those from 2 to 5 years, and group 4 , those aged 5-12 years. The main presenting symptoms in these groups are shown in Table I.

Groups 1 and 2 (90 cases).-In group 1 (45 cases) the gain in weight was unsatisfactory in all cases, although in several it was already improving and symptoms were subsiding spontaneously by the time the result of the urine examination was available. Positive blood cultures were obtained in three instances (E. coli 2, Staph. pyogenes 1), and one of these babies was jaundiced. As can be seen from Table I, the symptoms of the age-groups under 2 years were all the common symptoms of . early childhood-failure to thrive, with feeding problems in seven cases, fever, and vomiting were the most common. Fever was relatively unimportant in the newborn but was a presenting symptom in 17 of the remaining 45 infants, in nine of whom it was the only symptom. Three had febrile convulsions and one rigors. Disturbances of micturition were unusual. Thirst, however, was a presenting symptom in two cases. Two children presented with only chronic constipation. The common differential diagnoses in group 2 were teething, gastro-enteritis, pyloric stenosis, and maternal mismanagement, although pink disease, diabetes insipidus, idiopathic hypercalcaemia, and hiatus hernia were among those suggested on referral. Conversely, a

TABlE I.-Main Symptoms on Presentation

\begin{tabular}{|c|c|c|c|c|c|}
\hline & $\begin{array}{l}\text { Group } 1 \\
0-1 \mathrm{mth}\end{array}$ & $\begin{array}{c}\text { Group } 2 \\
1 \text { mth- } \\
2 \text { yrs }\end{array}$ & $\begin{array}{l}\text { Group } 3 \\
2-5 \text { yrs }\end{array}$ & $\begin{array}{l}\text { Group } 4 \\
5-12 \text { yrs }\end{array}$ & Total \\
\hline $\begin{array}{l}\text { Failure to thrive, feeding } \\
\text { problems }\end{array}$ & 24 & 16 & 3 & 一 & 43 \\
\hline $\begin{array}{c}\text { Screaming attacks, irrit- } \\
\text { ability }\end{array}$ & - & 6 & 2 & - & 8 \\
\hline Offensive or cloudy urine & - & 4 & 6 & - & 10 \\
\hline Diarrhoea.. & 8 & 7 & - & - & 15 \\
\hline Vomiting .. & 11 & 13 & 7 & 2 & 33 \\
\hline Fever $\quad \ldots$ & 5 & 17 & 25 & 33 & 80 \\
\hline Convulsions & 1 & 3 & 4 & 3 & 11 \\
\hline Haematuria $\quad \ldots$ & - & 3 & 7 & 4 & 14 \\
\hline Frequency or dysuria & - & 2 & 15 & 27 & 44 \\
\hline Enuresis $\ldots \quad \ldots \quad \ldots$ & - & - & 12 & 19 & 31 \\
\hline Abdominal pain ... & 一 & - & 10 & 29 & 39 \\
\hline Loin pain .. $\quad$. & - & & & 8 & 8 \\
\hline No. of children ... & 45 & 45 & 44 & 66 & 200 \\
\hline
\end{tabular}

number of young children not included in this series were thought to be possible cases of urinary infection with dysuria, and occasionally with frequency, in whom there was evidence of local irritation but the urinary findings were persistently normal.

Group 3 (44 cases).-Between 2 and 5 years feeding difficulties were less important, but fever remained a prominent presenting symptom and was the only one in five children. Four children with abdominal pain had frequency or enuresis of recent onset. One of the children with recurrent febrile convulsions had had full neurosurgical investigation before the significance of his urinary infection was appreciated. The main differential diagnosis in this group was from infection of the upper respiratory tract, which in fact co-existed in eight cases. In several cases the child was referred only when tonsillectomy had failed to cure a recurrent fever.

Group 4 ( 66 cases).-At the age of 5 years and over the conventional symptoms of acute pyelonephritis were usually found. Eleven of the children with disturbances of micturition had the classical picture of fever, loin or abdominal pain, frequency, and dysuria, but 15 children presented with abdominal pain and fever alone, eight with enuresis alone, and eight with fever as the only symptom. Three children presented with malignant hypertension. In one of these patients tonsillectomy had been carried out for recurrent fevers and in another ventriculography had been performed, as she had presented with hypertensive encephalopathy. The differential diagnosis in this group was principally from acute appendicitis, periodic syndrome, and true functional enuresis, although presenting diagnoses included Wilms's tumour, meningitis, and type I nephritis.

\section{Physical Signs}

The height of 85 children who had no radiological abnormality was measured on the Harvard School of Public Health growth charts. The mean percentile height for this group was the $42 \mathrm{nd}$. In the 88 children with radiological abnormalities who were measured the mean percentile height was the 35 th.

One or both kidneys were palpable in eight children, in six of whom renal abnormalities were demonstrated radiologically. 
Three cases had malignant hypertension and a further four were hypertensive. Congenital malformations of other systems were found in 26 cases; nine of these were severe neurological anomalies and six were cardiovascular. Two patients had Caffey's disease of infantile cortical hyperostosis. The only patient who died had multiple congenital malformations.

The blood urea was over $50 \mathrm{mg} . / 100 \mathrm{ml}$. during acute infection in four children with normal radiological findings (160 $\mathrm{mg} . / 100 \mathrm{ml}$. in one 3 -week old infant) and in 15 children subsequently shown to have radiological abnormalities.

\section{Radiological Investigations}

Intravenous pyelography was carried out in 175 patients, using the standard technique described by Hodson (1959). Abnormalities were found in 62 patients $(35 \%)$; the findings are listed in Table II.

\section{TABLE II.-Results of Intravenous Pyelography}

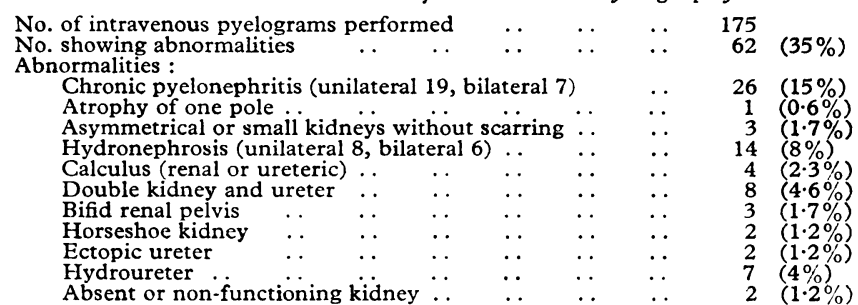

More than one abnormality was present in 10 cases.

For the purpose of this paper, chronic pyelonephritis has been diagnosed radiologically, according to Hodson's (1959) criteria of diminished cortical thickness, and clubbing or blunting of the corresponding calix (Fig. 3). The diagnosis was confirmed histologically (following nephrectomy or partial nephrectomy) in nine patients.

Micturating cystourethrography was performed in 165 cases, using Edwards's (1961) technique (Fig. 4). All the children were on maintenance chemotherapy and none had an active infection at the time of the investigation. A resting film of the full bladder and four films of the lower ureters, bladder-neck, and urethra were obtained during micturition, using the standard barium-meal serial film apparatus. Cineradiography was not used. Abnormalities were found in 76 children (46\%) and the findings are listed in Table III.

The normal bladder-neck funnels gradually into the urethra. A collar-like impression protruding into the urethral lumen at this level, with or without dilatation of the distal urethra, was

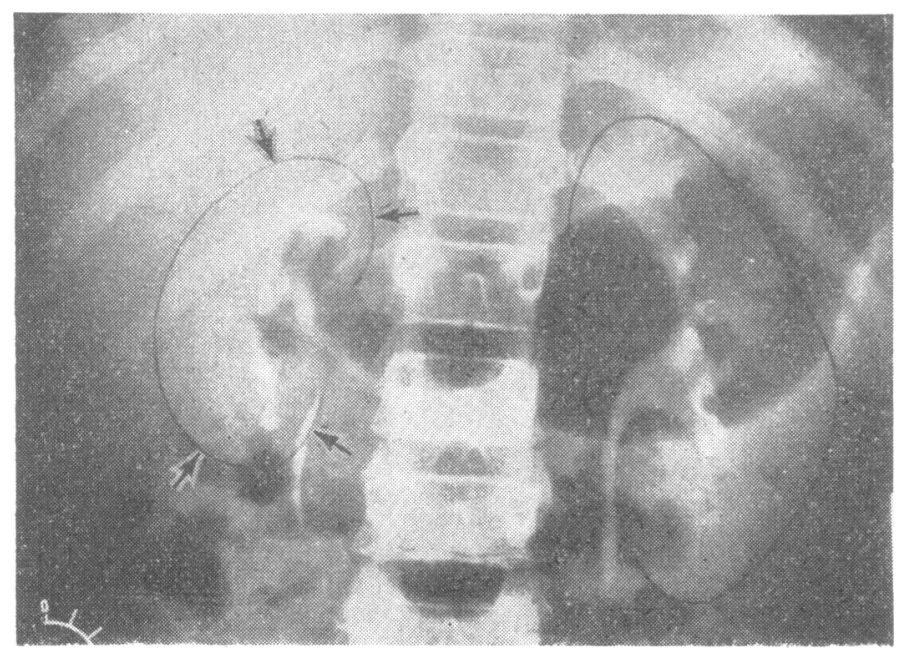

FIG. 3.-Chronic pyelonephritic scarring. Intravenous pyelogram. Both upper and lower poles of the right kidney are affected. A girl aged $7 \frac{1}{2}$ who, 14 months previously, had symmetrical kidneys. Arrows indicate extent of scars. The left kidney is hypertrophied. called primary bladder-neck hypertrophy. Residual urine and trabeculation were occasionally found in association with this appearance, and in 15 children there was vesico-ureteric reflux.

"Corkscrew" urethra is descriptive of the appearance of the posterior urethra in three children, in two of whom hydronephrosis was also found.

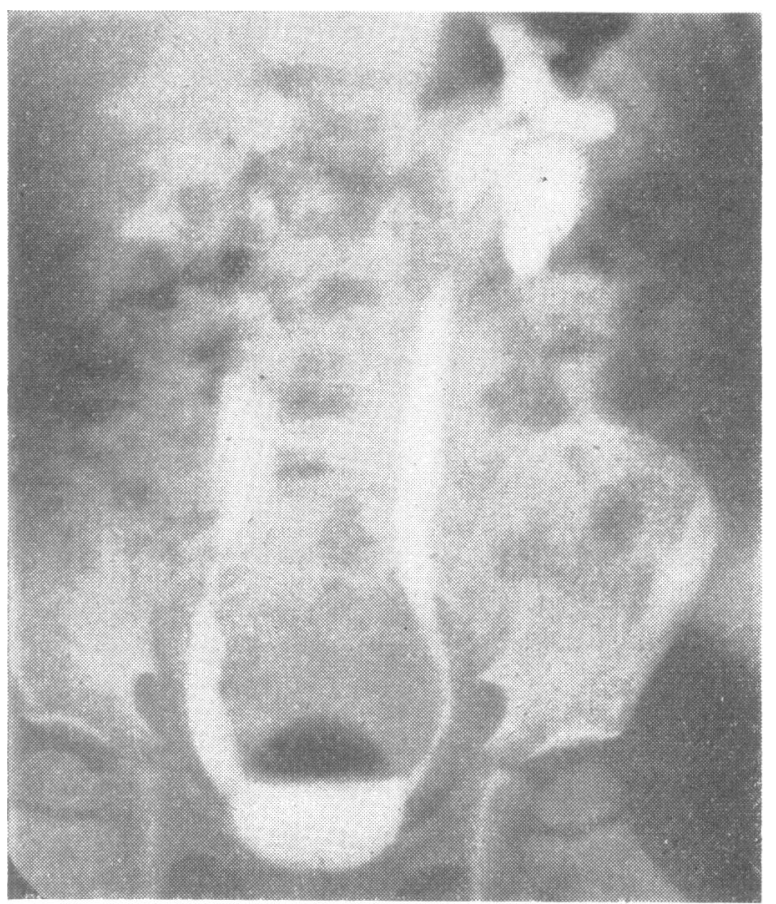

FIG. 4.-Micturating cystogram. Bladder filled through catheter. Gross vesico-ureteric reflux occurring during the act of micturition-" opacified" urine is distending the upper urinary tract.

TABLE III.-Results of Micturating Cystourethrography $\begin{array}{lllll}\text { No. of micturating cystograms performed } & \ldots & \ldots & \ldots & 165 \\ \text { No. showing abnormalities } & & & \end{array}$ $\begin{array}{llllllll}\text { No. showing abnormalities } & \ldots & \ldots & \ldots & \ldots & \ldots & 165 & 76 \\ \text { (46\%) }\end{array}$

Total showing reflux Reflux alone

Reflux and bladder-neck hypertrophy Total showing bladder-neck hypertroph Bladder-neck
Ectopic ureter

"Corkscrew" urethra

Urethral valves

Diverticula of bladder

Diverticulum of urethra

$$
\begin{array}{ll}
\ddot{40} & (24 \%) \\
16 & (10 \%)
\end{array}
$$$$
\text { ij }(\ddot{9} \%)
$$

In 153 children both intravenous pyelography and micturating cystography were carried out, an abnormality of one or both being found in $87(57 \%)$. An abnormality was demonstrated in the micturating cystogram in 28 children where the I.V.P. was normal, and an abnormality in the I.V.P. in 13 cases where the micturating cystogram revealed no abnormality (Table IV).

\section{TABLE IV.-Radiological Investigations}

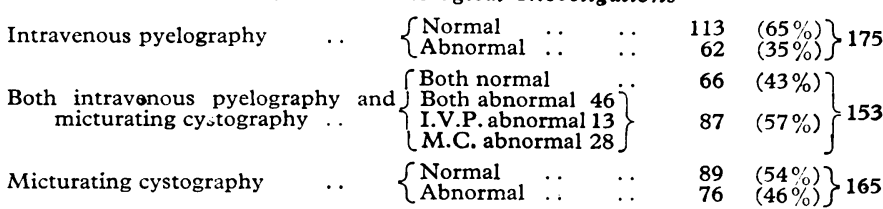

In 188 cases where one or both of these investigations were carried out an abnormality was found in $94(50 \%)$. Twentynine of these were in males with an abnormality rate of $56 \%$ and 65 were in females with an abnormality rate of $48 \%$. The most striking associations noted were between vesico-ureteric reflux and (a) chronic pyelonephritis, (b) hydronephrosis, or (c) duplex kidneys.

A radiological abnormality was demonstrated in $35 \%$ of the patients with a history of only one infection and in $65 \%$ of 
the patients with recurrent infection (Table V). Of the 34 boys investigated on apparently their first attack, 16 (47\%) showed a radiological abnormality, but only $17(28 \%)$ of the 60 girls.

\begin{tabular}{|c|c|c|c|}
\hline \multirow[b]{3}{*}{$\begin{array}{l}\text { No history of } \\
\text { previous attack .. }\end{array}$} & \multicolumn{2}{|c|}{ Radiological Investigation } & \multirow{2}{*}{ Total } \\
\hline & Normal & Abnormal & \\
\hline & $\left.\begin{array}{ll}18 & \mathrm{M} \\
43 & \mathrm{~F}\end{array}\right\} \quad 61(65 \%)$ & $\begin{array}{ll}16 & \mathrm{M} \\
17 & \mathrm{~F}\end{array} \quad 33(35 \%)$ & 94 \\
\hline $\begin{array}{l}\text { History of probable } \\
\text { previous attack ... }\end{array}$ & $\left.\begin{array}{rr}4 & M \\
16 & F\end{array}{ }^{20}\right\}_{2}$ & $\left.\begin{array}{r}7 \mathrm{M} \\
24 \mathrm{~F}\end{array}\right\} 31$ & \\
\hline $\begin{array}{l}\text { History of proved } \\
\text { previous attack .. }\end{array}$ & 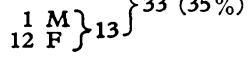 & $\left.\left.\begin{array}{rl}6 & \mathrm{M} \\
24 & \mathrm{~F}\end{array}\right\}^{30}\right\}^{61}$ & $\left.{ }_{43}\right\}^{9}$ \\
\hline Total & 94 & 94 & 188 \\
\hline
\end{tabular}

\section{Clinical Associations of Radiological Findings}

Associated abnormalities have already been referred to, but they would have given little guidance in detecting abnormal urinary tracts. Only two children had any deformity of the external ear. Three children with lumbar-spinal deformities had apparently normal urinary tracts, but four of the six children with congenital heart disease had vesico-ureteric reflux, as did both children with Caffey's disease.

There was no appreciable difference in the symptomatology of those in whom radiological abnormalities of the urinary tract were found and those in whom investigation proved normal. Of the 14 children with haematuria nine showed an abnormality, a ureteric calculus in one case only.

Three of the eight children with loin pain, 19 of those presenting with abdominal pain, and one of the three children presenting with rigors had normal investigations.

\section{Chronic Pyelonephritis}

A radiological diagnosis of chronic pyelonephritis was made in 26 children (4 males, 22 females). Symptoms started at or under the age of 5 in 16 cases, the youngest dating to the newborn period, a scar having appeared on intravenous pyelography by one year. The delay in presentation from the onset of symptoms is shown in Fig. 2. There were no characteristic symptoms or signs of pyelonephritis except for hypertension, which was present in six children. There was bacteriological evidence of recurrent infection in 11 patients and the history was highly suggestive of repeated infections in a further 13 . In one child there was persistent nocturnal enuresis at the age of 5 years, and in the final case there was no recurrence of infection after a severe attack at the age of 1 week. Thus out of a total of 94 children in our series with a history of recurrent infection $24(26 \%)$ showed radiological evidence of chronic pyelonephritis.

The presenting infection in these children with radiological chronic pyelonephritis was due to $E$. coli in 18 , Str. faecalis in three, Pr. vulgaris in one, and in three children who were receiving antibacterial drugs the cultures were sterile.

Scarring was unilateral in 19 (left-sided in 7, right-sided in 12) and bilateral in seven, a total of 33 pyelonephritic kidneys. Reflux was demonstrated from the bladder into the ureters of 27 out of 32 scarred kidneys, and there was reflux only into the ureter of the normal side in one case of unilateral scarring. In four patients with scarred kidneys no reflux could be demonstrated. Seven showed hypertrophy of the bladder-neck. In one patient micturating cystography was not performed.

\section{Vesico-ureteric Reflux}

This was demonstrated in $56(34 \%)$ out of the 165 children in whom micturating cystograms were carried out. It was present bilaterally in 29 and unilaterally in 27 . In 35 children the reflux extended up to the renal pelvis. In 16 there was also hypertrophy of the bladder-neck. The ages of these children (43 girls, 13 boys) ranged from 1 month to 11 years.

There was a history of recurrent infection in 38 children. Eighteen presented with apparently their first attack, though nine of these subsequently had a further infection. Thirtyseven children showed an abnormality on I.V.P., the most common being chronic pyelonephritis, which was found in 22 . Other abnormalities included hydronephrosis (seven cases) and double kidney and ureter (four cases).

Eighteen children in whom reflux was demonstrated, including five who also had bladder-neck hypertrophy, had normal upper urinary tracts on intravenous pyelography, although two of these had some degree of ureteric dilatation. Reflux was present at rest in 12 of these and extended up to the renal pelvis in 10 .

Ten of the 36 newborn infants who were investigated showed abnormalities, with ureteric reflux in five. Both I.V.P. and micturating cystogram were carried out in 23 newborn infants, and in only one instance did the I.V.P. show an abnormality where the cystogram was normal. In this case a hydronephrotic kidney was palpable.

\section{Discussion}

Many of the clinical features of this study have been observed previously; for instance, the female preponderance among children with urinary infections, which is less marked under the age of 1 year (James, 1959 ; Burke, 1961), the high incidence of the condition in infancy (Stansfeld, 1954), and its recurrent nature. Although the non-specific symptomatology in early childhood is also well recognized (Campbell, 1951), we found, in common with other authors, that only a minority were referred with the correct diagnosis. It is clear that infection of the urinary tract may be present in a child suffering any of the common symptoms of infancy, particularly fever or failure to thrive. In these the diagnosis will be made only if the condition is suspected and a specimen of urine is examined.

The relative merits of different bacteriological techniques (Kass, 1957 ; Pryles, 1960 ; Guttmann and Stokes, 1963) and the place of urine white-cell counting (Stansfeld and Webb, 1953 ; Houston, 1963) have been extensively studied and reviewed. In our experience, laboratory confirmation of the diagnosis rarely presents difficulty provided a fresh clean specimen of urine is collected before treatment is started. Catheterization is rarely necessary and is undesirable (Beeson, 1958). Clean-voided specimens suitable for bacterial examination can be obtained if care is taken in the cleansing of the perineum, and in young children urine may be collected into adhesive plastic bags. In order to avoid the growth of contaminants such specimens should be plated within two hours of voiding or they should be refrigerated if immediate plating is impracticable. It may at times be necessary to examine several specimens in order to obtain an unequivocal result.

The importance of radiology in urinary infections in childhood is evident from our results. Pyelography is of value mainly in detecting congenital malformations of the upper urinary tract, in assessing the size of the kidneys in relation to height and age (Hodson et al., 1962), and in showing irregularities of the renal outline and distortion of the calicine pattern (Hodson, 1959). Micturating cystourethrography provides information regarding the bladder, its capacity, ability to contract, and the presence of residue or trabeculation. It allows visualization of the outflow tract and urethra, and will demonstrate the occurrence of vesico-ureteric reflux at rest or during micturition. Both of these investigations are necessary for the evaluation of the whole urinary tract, and attempts to replace cystography by double micturition tests or by taking micturition films after intravenous pyelography have not been satisfactory. 
To justify the irradiation involved the radiological techniques and interpretation must be adequate to provide this information. In two of our children two complete series of normal pyelograms had already been carried out because of recurrent urinary infection. On referral free vesico-ureteric reflux was seen on cystography. In another case typical radiological pyelonephritic scarring had been overlooked and the kidneys were passed as normal. Irradiation can be minimized by reducing the size of field exposed, by limitation of the number of serial films taken, by careful preparation of the children, and by the use of an image-intensifier for cystography.

The high radiological abnormality rate in this series-50\% of the 188 children investigated-might be expected in view of the report of Kunin et al. (1962), but it should be noted that even among the 94 children in whom there was no history of previous infection we found abnormalities in $35 \%$. If radiological investigation is to be any guide to the further management of these cases, it does not seem reasonable to defer it until the infection has recurred. Furthermore, in view of the nonspecific symptomatology in early childhood it is never possible, after the first weeks of life, to be sure that an overt infection is in fact the initial one. It is therefore our practice to investigate all cases on their first presentation once the diagnosis is established and infection controlled.

Undoubtedly the most remarkable finding was the high incidence of radiological chronic pyelonephritis, which was present in $13 \%$ of the whole series, all aged 12 years or less, and in a quarter of the children with a history of recurrent infection. The great majority of these children also showed vesico-ureteric reflux on cystography, an association already observed by Hodson and Edwards (1960), and by Hinman and Hutch (1962).

Another significant finding was that vesico-ureteric reflux was present in $34 \%$ of the 165 children in whom micturating cystography had been carried out ; in no case was the examination performed during an active infection. This incidence is the same as that reported by Kjellberg et al. (1957). Reflux of urine from the bladder into the ureter, of whatever extent, is now accepted as an abnormal finding, and its role in chronic pyelonephritis and in recurrent urinary infections has been reviewed by Williams (1962), Rosenheim (1963), and Hutch et al. (1963). We believe it is important in these conditions, principally in predisposing to infection. It produces a false residue when the refluxing urine empties again into the bladder after completion of micturition, and it provides an obvious route for ascending infection. If this is so, the group of children with vesico-ureteric reflux but radiologically normal kidneys is obviously at considerable risk of developing chronic pyelonephritic scarring, unless the renal tract can be kept free from infection.

This study demonstrates again what has long been emphasized (Wharton et al., 1937 ; Keefer, 1957; Kleeman et al., 1960), that urinary infection in childhood is a far from benign condition. About a third of all such children may be expected to show vesico-ureteric reflux, and radiological chronic pyelonephritic scarring, with its serious prognosis, may be demonstrable in a quarter of recurrent cases. These are the children who can be expected to develop hypertension and renal failure in early adult life. Recognition, adequate treatment, and careful follow-up of urinary infection in childhood may significantly reduce this problem.

\section{Summary}

Analysis of the clinical features of 200 unselected children with urinary infection shows that the classical symptoms of acute pyelonephritis are uncommon under the age of 5 . The presenting symptoms began in the first year of life in almost half the children. Urinary infection was the diagnosis on referral in only a third.

Seven children were hypertensive and three of these had malignant hypertension.

Radiological investigation in 188 children revealed abnormalities of the urinary tract in $94(50 \%)$ and in $33(35 \%)$ of these there was no history of a previous infection.

Radiological chronic pyelonephritic scarring was present in 26 patients-that is, in $13 \%$ of the whole series, and in a quarter of all children with a history of recurrent infection.

Vesico-ureteric reflux was demonstrated in 56 children, associated in 22 cases with chronic pyelonephritis.

These findings re-emphasize the significance of urinary infection in childhood as a potentially serious condition.

We wish to thank Dr. B. E. Schlesinger, Dr. R. E. Bonham Carter, and Dr. L. B. Strang for permission to study cases under their care, and Professor M. L. Rosenheim, who kindly allowed us to include two cases under his care. This study has been greatly assisted by their continued encouragement and help.

\section{REFERENCËS}

Beeson, P. B. (1958). Amer. f. Med., 24, 1.

Burke, J. B. (1961). Lancet, 2, 1116.

Campbell, M. (1951). Clinical Pediatric Urology. Saunders, Philadelphia.

De Luca, F. G., Fisher, J. H., and Swenson, O. (1963). New Engl. 7. Med., 268, 75.

Edwards, D. (1961). Proc. roy. Soc. Med., 54, 1096.

Guttmann, D., and Stokes, E. J. (1963). Brit. med. F., 1, 1384.

Hinman, F., and Hutch, J. A. (1962). F. Urol., 87, 230.

Hodson, C. J. (1959). Proc. roy. Soc. Med., 52, 669.

Drewe, J. A., Karn, M. N., and King, A. (1962). Arch. Dis. Childh., 37, 616.

— and Edwards, D. (1960). Clin. Radiol., 11, 219.

Houston, I. B. (1963). Arch. Dis. Childh., 38, 600.

Hutch, J. A., Miller, E. R., and Hinman, F. (1963). Amer. F. Med., 34, 338.

James, U. (1959). Lancet, 2, 1001.

Kass, E. H. (1957). Arch. intern. Med., 100, 709.

Keefer, C. S. (1957). Bull. Fohns Hopk. Hosp., 100, 107.

Kjellberg, S. R., Ericsson, N. O., and Rudhe, V. (1957). The Lower Urinary Tract in Childhood.' Year Book Publishers, Chicago.

Kleeman, C. R., Hewitt, W. L., and Guze, L. B. (1960). Medicine (Baltimore), 39, 3.

Kunin, C. M., Zacha, E., and Paquin, A. J. (1962). New Engl. F. Med., 266, 1287.

Pryles, C. V. (1960). Pediatrics, 26, 441.

Rosenheim, M. L. (1959). Guy's Hosp. Rep., 108, 403.

- (1963). Brit. med. F., 1, 1433.

Stansfeld, J. M. (1954). Proc. roy. Soc. Med., 47, 631.

- and Webb, J. K. G. (1953). Arch. Dis. Childh., 28, 386.

Wharton, L. R., Gray, L. A., and Guild, H. G. (1937). f. Amer. med. Ass., 109, 1597.

Williams, D. I. (1962). Postgrad. med. F., 38, 520. 